\title{
Studying the processes of lipid peroxidal oxidation in the organism of fresh cows under the antioxidant impact
}

\author{
Lidiya Kashirina $^{1 *}$, Konstantin Ivanischev $^{1}$ and Kirill Romanov ${ }^{1}$ \\ ${ }^{1}$ Ryazan State Agrotechnological University named after P.A. Kostychev, Department of Anatomy and \\ Physiology of Agricultural Animals, 390044, Kostychev St., 1, Ryazan, Russia
}

\begin{abstract}
The article contains information on the state of the processes of lipid peroxidation (LPO) in fresh cows under the influence of stress reaction caused by labor and the beginning of the lactation period. To reduce oxidative stress in the body of fresh cows, antioxidants were used in the form of preparations "E-selenium" and "Butofan". The aim of the research was to determine the effect of vitamin-containing preparations "Eselenium" and "Butofan" on the productivity of fresh cows, the quality of milk and butter, made from it. The studies were carried out during the winter-stall period on one of the farms of Ryazan district of Ryazan region and involved 12 fresh black-and-white cows aged 4 years. The control group of animals was intact. As a result of the investigations, it was found that due to the action of the above preparations, which have antioxidant properties, the productivity parameters in the experimental groups of animals were higher compared to the control group, because they had an inhibiting effect on lipid peroxidation processes in the organism and activated the work of its own antioxidant system.
\end{abstract}

\section{Introduction}

At present, the relationship between biochemical blood parameters in the body of cows and productivity is well studied. To increase the productivity and improve the quality of milk, various preparations are used and their effect on metabolic processes in the body of animals, in particular lactating cows, is being studied. The processes of lipid peroxidation (LPO) occur constantly in all living organisms, however, in our opinion, this process remains insufficiently studied. With the participation of free radicals, the process is carried out according to the mechanism of a chain reaction, which proceeds in three stages: the first one is the start-up, the second one is chain branching, and the third one is chain interruption. At the first stage, mainly diene conjugates (DC), which are the primary and most important products of peroxidation, are formed. The process ends with formation of products of the secondary lipid oxidation, malondialdehyde (MDA). Strengthening the processes of LPO leads to a whole complex of changes at the cellular level: some decrease

\footnotetext{
* Corresponding author: kashirina@rgatu.ru
} 
in the activity of a number of enzymes, inhibition of protein synthesis, damage and inhibition of DNA synthesis, lysis of cell structures and deprivation of cell division processes [1].

LPO products are necessary for the implementation of many metabolic processes in the organism of animals, but their formation in large quantities has some toxic effect [2]. To protect against excessive formation of free radicals in living organisms, there is an antioxidant system. When prolonged exposure of adverse factors to a living organism, its functional reserves may be depleted and the body will not fully cope with the regulation of free radical reactions. At the same time, oxidative stress may occur, which will lead to disruption of cell membrane structures and this will result in the accumulation of toxic substances in cells, which are not fully digested by enzymes, will linger in the body, and subsequently affect the health and productivity of animals $[3,4]$. There is a number of factors that contribute to the enhancement of LPO in animals, in particular, the influence of physical activity, but the relationship of these processes with age-related features and various physiological states of the body has not been clarified.

In a normally functioning organism, the processes of LPO go at low speed in those cells where there are mainly phospholipids, i.e. unsaturated lipids. They influence the renewal of cellular membranes of the organism and their permeability, the regulation of the growth rate, and the processes of cell proliferation. Antioxidants reduce the concentration of free radicals $[5,6]$.

In order to resist oxidative stress during periods of intense physiological state, it is necessary to introduce some additional antioxidant preparations into animals' bodies $[1,7]$. A decrease in the antioxidant activity of the organism can occur when the spring deficit of antioxidants, stress, physical inactivity and excessive caloric intake. During these periods, there is an increase in free radical oxidation, a decrease in enzymatic oxidation and an increase in oxygen utilization in the body, which is explained by the disparity between the excess of fatty acids and oxygen in the tissue and the level of their consumption.

In our experimental studies vitamin-containing preparations "Butofan" and "Eselenium" possessing antioxidant properties were used. Their choice is due to the fact that "Butofan" contains butafosfan and vitamin B12 (cyanocobalamin). Butafosfan influences a number of metabolic processes: fat, protein and carbohydrate ones. It increases the resistance of the body by their stimulation. Vitamin B12 is involved in the activation of blood formation and the synthesis of methionine. It also affects the formation of glycogen in DNA synthesis.

The composition of "E-selenium" includes vitamin E, which affects the immune system and carbohydrate and fat metabolism, enhances the effect of a number of vitamins. Selenium has the ability to remove toxic substances from the body, in which its antioxidant properties are manifested.

The use of antioxidants in the form of vitamin-containing preparations helps to reduce oxidative processes in the body, increase overall resistance, better utilization of nutrients in diets and, consequently, increase productivity. At present, the problem of the influence of lipid peroxidation in the body on the quality of products obtained from animals remains insufficiently studied.

\section{Aim and objectives}

The aim of the research was to study the effect of vitamin-containing preparations "Eselenium" and "Butofan" on parameters of LPO in the body of fresh cows, productivity and 
fatty acid composition of cottage cheese made from milk obtained from cows under the influence of the above preparations.

The objectives of the research included the study of:

- concentrations of LPO products: DC and MDA in blood plasma and milk;

- antioxidants in blood plasma.

\section{Materials and methods}

The experiment was carried out on 12 fresh cows-analogues of black-and-white breed at the age of 3 years in LLC "Zarya", Ryazan district, Ryazan Region. Animals were divided into three groups of 4 heads each - two experimental and the control ones.

The duration of the experiment was 150 days. All animals were clinically healthy. The rations of animals were nutritionally balanced and met the standards of the RAAS [4].

The cows of the control group were intact, experimental animals were injected intramuscularly once a month for 5 months at a dose of $10 \mathrm{ml}$ per head, beginning from the second month of lactation. The first group received preparation "E-selenium", the second one got "Butofan".

Blood sampling was carried out from the jugular vein in the morning before feeding at the end of each month of lactation after calving, for 5 months starting from the second one. The selected blood was stabilized with a $10 \%$ solution of ethylenediaminetetraacetic acid (EDTA). The analysis was performed with hematological blood analyzer "Abacus". Plasma was investigated with biochemical analyzer "ChemWell".

The concentration of diene conjugates (DC) - the primary products of LPO and malondialdehyde (MDA) - the secondary product was determined in blood plasma and milk of cows. Antioxidants: $\alpha$-tocopherol, catalase, and ceruloplasmin were also detected in blood plasma.

The optical density of the solutions, when determining the concentration of malondialdehyde, diene conjugates and $\alpha$-tocopherol, was made with "Apel PD-303 UV" spectrophotometer.

Hematological studies were carried out in the laboratory of veterinary clinic "VITA" at Ryazan State Agrotechnological University.

\section{Results and discussion}

In the first month after calving, the content of DC in the blood plasma of experimental and control cows was approximately at the same level. In the second month of lactation, its concentration in the blood plasma of all groups of cows increased from 9.4 units in the first experimental group to 19.6 units in experimental group 2, and 17.1 units in the control (Table 1). After blood sampling from cows in the second month of lactation and making sure that the concentration of DC in the blood plasma increases, the animals of the experimental groups were injected with the above preparations, at a known concentration. This significantly affected the content of DC in the blood plasma. In the third month of lactation the DC concentration of the animals of the experimental groups decreased significantly. So, when introducing "E-selenium", it decreased by $20 \%$ in experimental group 1 . When introducing "Butofan" in experimental group 2, the DC value decreased by $26 \%$. The DC value in the control increased as compared with the first month of lactation by $17.4 \%$.

The third month is the height of lactation, when the cows' yield of milk is the highest and, under the influence of injected antioxidants, there was a decrease in peroxidation products in the blood plasma of animals of the experimental groups. In the fourth month of lactation, the concentration of primary LPO products in all groups increased insignificantly, 
but in the experimental groups it continued to be kept at a lower level as compared to the control. In the fifthmonth, the level of DC content in the experimental groups slightly increased, while in the control it remained not high, like that in the fourthmonth of lactation.

Table 1. The content of primary LPO products (DC) in the blood plasma (in standard units ${ }^{1}$ )

\begin{tabular}{|c|c|c|c|c|c|}
\hline Group & $\begin{array}{c}1^{\text {st }} \text { month } \\
\text { of lactation }\end{array}$ & $\begin{array}{c}2^{\text {nd }} \text { month } \\
\text { of lactation }\end{array}$ & $\begin{array}{c}3^{\text {rd }} \text { month of } \\
\text { lactation }\end{array}$ & $\begin{array}{c}4^{\text {th }} \text { month of } \\
\text { lactation }\end{array}$ & $\begin{array}{c}5^{\text {th }} \text { month } \\
\text { of lactation }\end{array}$ \\
\hline Experimental 1 & $108.9 \pm 8.3$ & $118.3 \pm 1.6$ & $94.3 \pm 6.6^{*}$ & $119.8 \pm 7.3$ & $120.3 \pm 10.2$ \\
\hline Experimental 2 & $102.5 \pm 9.9$ & $122.1 \pm 5.4$ & $90.7 \pm 1.6^{* * *}$ & $121.9 \pm 11.8$ & $122.0 \pm 2.4$ \\
\hline Control & $103.8 \pm 7.7$ & $120.9 \pm 2.7$ & $121.5 \pm 3.6^{* * *}$ & $124.9 \pm 11.0$ & $124.9 \pm 9.9$ \\
\hline
\end{tabular}

standard unit -1 absorbance unit $\times 1000$. The reliability of the difference of parameters compared with the control group: $*-p \leq 0.05, * *-p \leq 0.01, * * *-p \leq 0.001$. The designations in the following tables are the same.

When determining the content of secondary LPO products (MDA) in the blood plasma, it was found that in the period after calving in all three groups, this parameter was approximately at the same level (Table 2). In the secondmonth in all groups the value of this parameter increased, but was approximately at the same level. In the thirdmonth with the introduction of vitamin-containing preparations to the cows of the experimental groups, the concentration of MDA in the blood plasma decreased, moreover, in experimental group 2 it decreased by $34 \%$ as compared with that in the period before the introduction of the preparation. In the fourthmonth of lactation the amount of MDA in the blood plasma in experimental group 1 continued to decrease, and in the control group it continued to increase insignificantly. In the fifthmonth, the value of this parameter in experimental group 1 was the lowest, which indicates the active work of preparation "Butafan".

Table 2. The content of secondary LPO products (MDA) in the blood plasma, in $\mu \mathrm{mol} / 1(\mathrm{n}=4)$

\begin{tabular}{|c|c|c|c|c|c|}
\hline Group & $\begin{array}{c}1^{\text {st }} \text { month } \\
\text { of lactation }\end{array}$ & $\begin{array}{c}2^{\text {nd }} \text { month } \\
\text { of lactation }\end{array}$ & $\begin{array}{c}3^{\text {rd }} \text { month } \\
\text { of lactation }\end{array}$ & $\begin{array}{c}4^{\text {th }} \text { month of } \\
\text { lactation }\end{array}$ & $\begin{array}{c}5^{\text {th }} \text { month } \\
\text { of lactation }\end{array}$ \\
\hline Experimental 1 & $3.89 \pm 0.24$ & $3.99 \pm 0.25^{*}$ & $2.93 \pm 0.17$ & $2.94 \pm 0.25$ & $3.10 \pm 0.64^{*}$ \\
\hline Experimental 2 & $3.75 \pm 0.16$ & $4.31 \pm 0.44$ & $2.88 \pm 0.25^{* *}$ & $2.86 \pm 0.48$ & $2.76 \pm 0.33$ \\
\hline Control & $3.71 \pm 0.66$ & $3.82 \pm 0.46^{*}$ & $3.83 \pm 0.14$ & $3.84 \pm 0.24$ & $3.86 \pm 0.49$ \\
\hline
\end{tabular}

The blood plasma always contains its own antioxidants. To determine the effectiveness of using vitamin-containing preparations, the concentration of antioxidants: $\alpha$-tocopherol, catalase, and ceruloplasmin was determined (Table 3). The choice of these antioxidants is due to the fact that vitamin $\mathrm{E}$ or $\alpha$-tocopherol slows down the oxidation of polyunsaturated fatty acids and is involved in the stabilization of cell membranes. Catalase prevents the process of accumulation of hydrogen peroxide in the body, which leads to destruction and cell death, decomposing it into molecular oxygen and water [8]. Ceruloplasmin is a specific copper-containing plasma protein. It increases the stability of cell membranes, participates in immune response reactions, and has a strong antioxidant effect.

The content of $\alpha$-tocopherol in the blood plasma of cows changed insignificantly over the entire period of the experiment and remained at approximately the same level in all 
groups. Its concentration in the cows of experimental group 2 in the first and fifth months of lactation was higher than that of the cows of experimental group 1 and the control group, and in the fifth month - significantly $(\mathrm{P} \leq 0.001)$.

Table 3. The content of antioxidants in the blood plasma $(n=4)$

\begin{tabular}{|c|c|c|c|}
\hline Group & $\begin{array}{c}\text { Activity of } \\
\alpha \text {-tocopherol, } \\
\mu \mathrm{mol} / 1\end{array}$ & $\begin{array}{c}\text { Activity of cata- } \\
\text { lase, } \\
\mu \mathrm{mol} / 1 * \mathrm{sec}\end{array}$ & $\begin{array}{c}\text { Activity of cerulo- } \\
\text { plasmin, } \\
\mathrm{nmol} / 1 * \mathrm{sec}\end{array}$ \\
\hline \multicolumn{4}{|c|}{$2^{\text {nd }}$ month of lactation } \\
\hline Experimental 1 & $108.3 \pm 8.2$ & $25.4 \pm 3.7$ & $122.4 \pm 11.6$ \\
\hline Experimental 2 & $108.0 \pm 5.0^{* * *}$ & $25.6 \pm 5.0$ & $121.5 \pm 8.1$ \\
\hline Control & $108.8 \pm 8.2$ & $26.6 \pm 3.0$ & $120.1 \pm 2.0^{*}$ \\
\hline \multicolumn{4}{|c|}{$3^{\text {rd }}$ month of lactation } \\
\hline Experimental 1 & $81.9 \pm 9.6$ & $27.4 \pm 2.2$ & $132.8 \pm 11.4$ \\
\hline Experimental 2 & $81.2 \pm 15.2$ & $28.6 \pm 4.0$ & $138.5 \pm 31.6$ \\
\hline Control & $80.8 \pm 1.0^{* *}$ & $22.4 \pm 5.9$ & $142.5 \pm 8.3$ \\
\hline \multicolumn{4}{|c|}{$4^{\text {th }}$ month of lactation } \\
\hline Experimental 1 & $90.6 \pm 3.7$ & $28.0 \pm 11.0$ & $136.4 \pm 18.2$ \\
\hline Experimental 2 & $90.4 \pm 8.1$ & $34.5 \pm 4.9$ & $139.5 \pm 12.1$ \\
\hline Control & $80.5 \pm 2.9^{* *}$ & $15.9 \pm 7.3$ & $161.0 \pm 4.8^{* * *}$ \\
\hline \multicolumn{5}{|c|}{$5^{\text {th }}$ month of lactation } \\
\hline Experimental 1 & $83.6 \pm 7.2$ & $28.7 \pm 4.6$ & $120.1 \pm 6.8^{* *}$ \\
\hline Experimental 2 & $84.6 \pm 6.9^{* * *}$ & $34.9 \pm 2.8$ & $123.5 \pm 2.9^{* *}$ \\
\hline Control & $80.2 \pm 3.2$ & $15.6 \pm 3.3$ & $176.1 \pm 25.7$ \\
\hline
\end{tabular}

The activity of $\alpha$-tocopherol or vitamin $\mathrm{E}$ in all samples in the period after calving was at the same level. At the end of the second month of lactation, after the injection of preparations, there was a decrease in the concentration of vitamin $\mathrm{E}$ in all groups starting from 3 months, which was associated with the consumption of tocopherol to inhibit the active processes of LPO in the third month after calving [8]. In month 4, the activity of $\alpha$ tocopherol in the experimental samples increased in experimental group 1 by $8.0 \mu \mathrm{mol} / 1$, and in experimental group 2 by $9.0 \mu \mathrm{mol} / 1$. In the following month, a similar trend occurred. The content of a-tocopherol in the blood plasma of cows in the $3^{\text {rd }}$ month of lactation after calving decreased, but in the fourth and fifth months it slightly increased due to the redistribution of vitamin $\mathrm{E}$ between tissue reserves and plasma and the mobilization of its reserves in response to increased lipid peroxidation [9].

Catalase activity in the experimental groups increased significantly, starting from the 3rd month of lactation, especially in experimental group 2, where "Butofan" was used. So, in month 4 its concentration was $19 \%$ higher than in experimental group 2 and kept approximately at the same level for the entire period of the experiment. The activity of catalase in the control after 3 months of lactation fell and by month 5 it was $44 \%$ lower than in experimental group 1 and $46 \%$ lower than in experimental group 2. Despite the elevated level of primary and secondary LPO in blood, catalase activity in the 3rd month of lactation in cows of the second group increased dramatically and remained at a high level until the end of the experiment in response to the administration of preparation "Butofan". Since the level of main antioxidants in the blood plasma of cows of this group has remained high, "Butofan" has more pronounced antioxidant.

The activity of ceruloplasmin increased in all groups after 3 months of lactation. These changes were significant in the control group and amounted to $22.4 \mu \mathrm{mol} / 1 * \mathrm{sec}$. In experimental group 1 , this parameter increased by $10.4 \mu \mathrm{mol} / 1 * \mathrm{sec}$ as compared to the period 
before the administration of the preparation, and in experimental group 2 it increased by $17.0 \mu \mathrm{mol} / 1 * \mathrm{sec}$, supporting this trend for 4 months. By month 5 this parameter decreased and reached the level of initial values in the experimental groups. The cows in the control group had a steady monthly increase in it and by month 5 the difference with the third month after calving was $33.6 \mu \mathrm{mol} / 1 * \mathrm{sec}$.

Alongside tocopherol and catalase, the concentration of ceruloplasmin was kept at a high level up till month 5 of lactation. The increased content of ceruloplasmin in the control in month 4 of lactation is associated, as we believe, with a decrease in the activity of catalase and tocopherol, to a small extent [10]. By the fifth month of lactation the experimental groups had a sharp decrease in the activity of ceruloplasmin in comparison with the control.

Ceruloplasmin inhibits lipid peroxidation due to pronounced antioxidant activity. In the fifth month of lactation, the antioxidant activity of ceruloplasmin decreased significantly due to the depletion of reserves for its biosynthesis. During this period, both the primary and secondary processes of LPO were more active. Consequently, vitamin E, which is a part of "E-Selenium", influenced the production of other antioxidants and controlled the level of LPO in the blood plasma of cows throughout the experiment, reducing both primary and secondary products. And "Butofan" maintained a high level of the main antioxidants in the blood plasma of cows from experimental group 2.

\section{Conclusions}

One of the ways to increase productivity and at the same time preserve the health of animals is the use of antioxidant preparations, which not only interfere with and neutralize the products of peroxidation in the body, but improve the blood composition.

The use of antioxidants for fresh cows is advisable, since oxidative reactions in their bodies are most pronounced against the background of involutional processes in the mammary gland during the post-partum lactation period. An important role in the involution mechanism is assigned to the processes of auto phagocytosis, which are usually accompanied by an increased intensity of LPO.

Antioxidant preparations "E-selenium" and "Butofan" normalize metabolic and regenerative processes in the body, has a stimulating effect on protein, carbohydrate and fat metabolism.

The use of the above preparations reduces the intensity of lipid peroxidation processes in the blood plasma of lactating cows, contributing to the preservation of health and increase in productivity. When transferring from the blood to the mammary gland cells by the method of active transport using specific receptor proteins, antioxidants reduce the negative impact of lipid peroxidation processes in the organism of animals and, as a result, protect it. This increases the amount of unsaturated fatty acids in milk and products derived from it. Therefore, the use of antioxidants in the practice of dairy cattle breeding allows to keep the animals healthy and to obtain high quality products.

Experimental studies have established that the use of preparations with antioxidant activity reduces LPO processes in the body, inhibits them at different stages, and free radicals do not accumulate in the body. The use of vitamin-containing preparations "Eselenium" and "Butofan" had some positive effect on the reduction of lipid peroxidation processes in the body of fresh cows. "Butofan" was highest activity. When using it, the formation of primary LPO, diene conjugates, significantly decreased, the content of $\alpha$ tocopherol significantly increased and the activity of catalase increased. The use of this preparation kept parameters of antioxidant activity in the body of fresh cows at a high level until the end of the experiment, which confirms their more pronounced antioxidant properties. This increased the amount of unsaturated fatty acids in the cottage cheese 
obtained from whole and skim milk of fresh cows under the influence of antioxidants, which improved its quality.

\section{References}

1. R.Kh. Karmoliyev,. Agric. Biology. 2, 19-28 (2002)

2. B. Kucsunska, T. Nalecs-Taruacka, Relationship between content of phospholipids in milk and stability of milk fat globule membrane and the effects of some factors on the frequency of their destabilization. Annals of Warshaw agr. univ., 289-294 (Warshaw, 2009)

3. L.G. Kashirina, A.V. Antonov, I.A. Plyushchik, Herald of RSATU. 3(19), 24-27 (2013)

4. A.P. Kalashnikov, V.I. Fisinin, V.V. Scheglov, et al., Norms and diets for feeding farm animals (Moscow, Kolos, 2003)

5. Yu. A. Vladimirov, Herald of the Rus. Acad. of Med. Sc. 7, 43-57 (1998)

6. M. Naziroglu, S. Gur, Deutsch. Tierarztl. Wochenschr. 107(9), 374-376 (2000)

7. L.G. Kashirina, K.A. Ivanischev, K.I. Romanov, Herald of RSATU, 4, 15-19 (2016)

8. P.P. Golikov, B.V. Davydov, S.B. Matveev, Questions of Med.Chem. 33, 47-50 (1987)

9. G.N. Cruz, A.G. Khramtsov, S.V. Karpychev, Technology of milk and dairy products. (Moscow, Kolos, 2006)

10. S.M. Yanovaya, Chemistry of fats, 114-115 (Moscow, NORMA Publishing House, 2002) 